\title{
Requisitos de um Ambiente Virtual de Aprendizagem para TV Digital Interativa
}

\author{
Airton Zancanaro ${ }^{1}$ \\ Paloma Maria Santos ${ }^{2}$ \\ José Leomar Todesco ${ }^{3}$
}

\section{Resumo}

O processo de ensino/aprendizagem a distância alcançou no mundo proporções jamais esperadas graças, principalmente, à evolução das Tecnologias da Informação e Comunicação (TICs). A não-obrigatoriedade da presença física em horários predeterminados abriu precedente para que inúmeras pessoas se integrassem a esse novo cenário, onde a educação, por meio dos Ambientes Virtuais de Aprendizagem (AVA), ganha destaque. Considerando a TV Digital como uma mídia bastante atrativa para suportar também a Educação a Distância $(\mathrm{EaD})$, o presente artigo, partindo de uma revisão bibliográfica, buscou levantar os requisitos necessários para a disponibilização de um AVA na TV Digital Interativa (TVDI). Considerando as particularidades desta mídia, apresentamos como resultado os requisitos tecnológicos e pedagógicos, cuja explicitação visa auxiliar no desenvolvimento de ambientes propícios para 0 ensino/aprendizagem.

Palavras-chaves: educação a distância, ambiente virtual de aprendizagem, tv digital interativa, sociedade do conhecimento.

\section{Requirements of a Virtual Learning Environment for Interactive Digital TV}

\begin{abstract}
The process of teaching and learning in the world has reached proportions never expected mainly because of the ICT developments. The non-mandatory physical presence at a predetermined times opened precedent for many people to integrate this new scenario, where education, through the virtual learning environment, is highlighted. Considering Digital TV as a very attractive medium to also support distance education, this article, from a literature review, sought to raise the requirements for the provision of a virtual learning environment in Interactive Digital TV. Considering the particularities of this medium, it is present as a result technological and pedagogical requirements, whose explicit aims to assist in the development of environments conducive to teaching and learning.
\end{abstract}

Keywords: distance education, virtual learning environment, interactive digital tv, knowledge society.

\section{Introdução}

\footnotetext{
${ }^{1}$ PPGEGC - Programa de Pós-Graduação em Engenharia e Gestão do Conhecimento - UFSC. E-mail: airtonz@egc.ufsc.br

${ }^{2}$ PPGEGC - Programa de Pós-Graduação em Engenharia e Gestão do Conhecimento - UFSC. E-mail: paloma@egc.ufsc.br

${ }^{3}$ PPGEGC - Programa de Pós-Graduação em Engenharia e Gestão do Conhecimento - UFSC. E-mail: tite@lec.ufsc.br
} 
Diferentemente da sociedade industrial cujas fontes de riquezas são basicamente o capital, os recursos naturais e a mão de obra, a sociedade do conhecimento se caracteriza por concentrar seus esforços na criação e no compartilhamento do conhecimento e da rede de relacionamentos.

Educar neste contexto, vai além de instruir as pessoas para o uso das novas tecnologias. Envolve formar os indivíduos para aprender a conhecer, aprender a fazer, aprender a viver juntos e aprender a ser, de modo a prepará-los para a contínua e acelerada transformação do mundo que os cerca.

Ainda que a tecnologia ofereça suporte para o ambiente de ensino/aprendizagem, ela deve buscar dar apoio, ampliar e enriquecer os espaços de convivência, privilegiando a atividade do indivíduo na construção do conhecimento, permitindo que este tenha um papel ativo em todo o processo. Tais recursos devem ser contemplados no AVA a ser disponibilizado.

Uma mídia que vem levantando grandes discussões nesse quesito é a TVDI, pelo fato de ela ter como principal benefício a participação do usuário no conteúdo transmitido pela emissora. As transmissões neste formato requerem que o usuário utilize dispositivos fixos (set-top-box) ou móveis (celulares, PDAs, entre outros), que no caso brasileiro, possuem o middleware Ginga incorporado.

De posse destes dispositivos, o usuário poderá interagir com diversos conteúdos e serviços oferecidos. Para tal, a TVDI deve contemplar um ambiente que dê suporte a requisitos gerais, além de outros ligados a questões técnicas e pedagógicas do próprio sistema. Tendo em vista identificar tais requisitos, este artigo busca reunir e explicitar os requisitos necessários para a disponibilização de um AVA na TVDI.

Para tal, na seção 2 apresenta-se um rápido histórico e alguns conceitos de $\mathrm{EaD}$ e t-learning. A seção 3 aborda o AVA, suas características e aplicabilidades. Na seção 4, tem-se os requisitos técnicos e pedagógicos que foram identificados e, finalmente, a seção 5 trata das conclusões e trabalhos futuros.

\section{EAD e t-learning}

Hoje, mais do que transmitir informação, a educação visa preparar para o futuro, desenvolver capacidades, cognitivas, afetivas e sociais. Por isto, é possível afirmar que as TICs trouxeram para a área da educação novas ferramentas que facilitam e enriquecem os processos de ensino/aprendizagem (Torres, 1993).

A educação continuada ou permanente, aprendizagem ao longo da vida e sociedade do conhecimento possibilitam que o indivíduo não tenha uma data para a conclusão dos seus estudos e sim, tenha na educação uma forma de sobrevivência (Filatro, 2004). Para auxiliar neste processo surgiu a telemática, abrindo possibilidades para que a EaD se desenvolvesse e atingisse um número maior de pessoas, auxiliando assim a contornar os problemas enfrentado pela educação presencial.

Neste sentido a EaD é definida por Brasil (2005) como

[...] modalidade educacional na qual a mediação didáticopedagógica nos processos de ensino e aprendizagem ocorre com a utilização de meios e tecnologias de informação e comunicação, com estudantes e professores desenvolvendo atividades educativas em lugares ou tempos diversos.

Com a inserção das TICs na EaD, principalmente a utilização das diversas mídias eletrônicas como computadores, Internet, TVDI, CD-ROM, fitas de áudio e vídeo bem como o surgimento de softwares de fácil utilização, fez com que o surgisse um termo novo, o "e-learning" (Belloni, 1999). 
Para Joci (2002, p.179/16) o e-learning é a "[...] utilização das tecnologias de multimídia e da Internet, para melhorar a qualidade da aprendizagem, facilitando o acesso a recursos e a serviços, bem como o intercâmbio e colaboração a distância". Neste caso, o estudante tem flexibilidade, não necessitando estar no mesmo local geograficamente e/ou no mesmo horário, diferentemente do que ocorre com a sala de aula tradicional.

Da mesma forma, a televisão pode ser utilizada como mídia eletrônica para suporte ao e-learning, uma vez que ela é tida como o meio de comunicação de massa mais popular e acessível ao público. Com o surgimento da TVDI, cria-se um importante instrumento de ensino/aprendizagem disponível para o uso dos educadores. Por meio dela é possível transmitir áudio, vídeo e dados levando o conhecimento a um número maior de pessoas, promovendo assim a inclusão social.

A aprendizagem baseada na TVDI, conhecida como "t-learning", significa acesso a vídeos interativos e materiais didáticos através do uso da tecnologia computacional, utilizando para isso, um dispositivo de fácil uso que é a televisão (Bates, 2003; Aarreniemi-Jokipelto, 2005; Damásio; Quico, 2004). Desta forma, o t-learning é um subconjunto do e-learning proporcionando a convergência entre a TV Digital, Internet e celular.

Assim como na Web, o t-learning necessita de um AVA onde os estudantes podem, dentre outras coisas: interagir com o conteúdo pedagógico, trocar informações com o professor/tutor, envolvendo principalmente o aprendiz no processo de ensino/aprendizagem.

\section{Ambientes Virtuais de Aprendizagem (AVA)}

O processo de ensino/aprendizagem a distância alcançou no mundo proporções jamais esperadas graças, principalmente, à evolução das TICs. A disjunção entre o espaço e o tempo, provenientes do advento das telecomunicações, permitiu que a informação e o conteúdo simbólico pudessem ser transmitidos para distâncias cada vez maiores num espaço de tempo cada vez menor.

A não-obrigatoriedade da presença física em horários predeterminados abriu precedente para que inúmeras pessoas se integrassem a esse novo cenário, onde a educação, por meio dos AVAs, ganha destaque.

Um AVA pode ser definido como uma mídia que habita o ciberespaço para promover o ensino/aprendizagem. Ele ocorre por meio de interfaces que favorecem a interação e a colaboração a distância entre os diversos atores do processo e o conteúdo a ser aprendido, incluindo ferramentas para atuação autônoma, oferecendo recursos para aprendizagem coletiva e individual (Noronha; Vieira, 2005).

De acordo com Schlemmer (2005), o AVA tem como objetivos: apoiar, ampliar e enriquecer os espaços de convivência, privilegiando a atividade do indivíduo na construção do conhecimento, a partir de propostas inter e transdisciplinares; oportunizar um espaço de desenvolvimento-pesquisa-ação-capacitação de forma sistemática e sistêmica, vivenciando uma aprendizagem que implique rupturas paradigmáticas; favorecer $\mathrm{o}$ acesso às tecnologias educacionais, aos vários agentes sociais, na perspectiva da construção do conhecimento e das competências sociais.

Tannous e Ropoli (2005) ao discutir como se dá a interação entre o estudante e a AVA, lembram que Célestin Freinet, pedagogo francês, já na sua época, buscava dar ênfase não nas disciplinas, mas sim na motivação, na riqueza do ambiente educacional, nos materiais e nas técnicas presentes no ambiente em função da educação, uma vez que desses elementos decorrerão todas as aquisições de conhecimento. 
Para Dillenbourg (2000), os AVAs, em sua essência, devem contemplar: espaços sociais e de informação bem estabelecidos e bem representados; interações educativas dentro do ambiente; estudantes atores, que coparticipem da criação do espaço virtual; atividades que enriqueçam os conteúdos abordados; integração de múltiplas tecnologias e abordagens pedagógicas.

\section{Requisitos de um AVA voltado para a TVDI}

Requisitos podem ser definidos como "uma condição para se alcançar determinado fim" (Houaiss, 2009, p. 1650) ou, no domínio da Engenharia de Software, como "uma série de sentenças que descrevem de maneira clara, concisa, consistente e não ambígua todos os aspectos significativos de um sistema a ser desenvolvido" (Rocha, Maldonado e Weber, 2001, p. 44).

Pensando no desenvolvimento de cursos de EaD voltados para a TVDI, cujo ambiente e a tecnologia envolvida deverão dar suporte, Aarreniemi-Jokipelto (2006) define alguns requisitos de maneira geral, quais sejam: a) a interação e a comunicação necessitam ser viabilizadas pela tecnologia; b) a tecnologia deverá dar suporte à avaliação; c) o conteúdo pedagógico juntamente com as tarefas necessitam ser enviadas e apresentadas aos estudantes; d) permitir a reusabilidade do conteúdo em diferentes disciplinas e dispositivos.

Para oferecer tais conteúdos, a TVDI deve contemplar um ambiente que dê suporte a esses requisitos gerais, além de outros ligados a questões técnicas e pedagógicas do próprio sistema. Tendo em vista identificar tais requisitos, as subseções que seguem tratarão de reunir e explicitar o que se encontrou na literatura relativa a esse domínio de aplicação.

\subsection{Requisitos tecnológicos}

Os requisitos tecnológicos são os elementos referentes e necessários à infraestrutura de tecnologia para prover a criação, desenvolvimento e fruição de conteúdo para TVDI. Assim, um AVA voltado para a TVDI tem como requisitos tecnológicos: canal de transmissão, interação/comunicação, segurança das informações, confiabilidade e usabilidade.

\section{a) Canal de transmissão}

É o meio pelo qual a programação de uma emissora de televisão é transmitida. Enquanto na TV analógica um canal transmite apenas sons e imagens, na TVDI ocorre também a transmissão de dados.

Em se tratando de cursos utilizando o t-learning, o canal de transmissão é um requisito básico, pois neste caso, a TVDI é considerada como a principal tecnologia, podendo a Internet ser utilizada como secundária (Aarreniemi-Jokipelto, 2006).

É através do canal de transmissão que aplicativos computacionais são enviados para os dispositivos fixo e móveis permitindo que o usuário interaja com eles pelo controle remoto ou através de outras interfaces.

\section{b) Interação/Comunicação}

Aarreniemi-Jokipelto (2006) define quatro tipos possíveis de interação no $t$ learning: entre o estudante com o material didático: ocorre por uma via unidirecional, não sendo necessário um canal de retorno. $\mathrm{O}$ estudante realiza atividades no formato de autoavaliação, na qual o AVA fornece os feedbacks, além da navegação pelo conteúdo; 
entre os estudantes e o professor/tutor e entre os próprios estudantes: necessitam obrigatoriamente de um canal bidirecional de interatividade. Atividades como troca de mensagens entre os participantes do curso e o envio de avaliações com objetivos formais de aprendizagem são algumas das atividades que podem ser realizadas com o auxílio do canal de retorno; entre o estudante e o ambiente de aprendizagem: reflete o conceito da sala de aula on-line, possibilitando o uso de várias mídias como vídeo, áudio, textos e imagens facilitando o aprendizado (Filatro, 2008).

\section{c) Segurança dos Dados}

Em um AVA voltado para cursos de t-learning, a segurança dos dados inclui as características de integridade, autenticação e privacidade.

Em relação à integridade dos dados, o sistema deve garantir que informações de acessos e registros de atividades desenvolvidas sejam armazenadas de maneira correta e confiável. No que diz respeito à autenticação, o sistema deve permitir que, de acordo com as características do curso, apenas pessoas autorizadas tenham acesso às informações (Belda, 2009). Em relação à privacidade, o sistema deverá garantir que as informações sigilosas trafeguem em segurança e ainda, que os dados dos participantes não sejam acessados ou alterados de forma indevida (Tonieto, 2006).

\section{d) Confiabilidade}

Entende-se por confiabilidade a probabilidade do software em concluir a sua missão de forma exitosa, uma vez que ele tenha sido iniciado. No caso dos computadores pessoais, as falhas nos sistemas e a demora no acesso às informações devido à baixa velocidade são toleráveis, por outro lado, para os usuários da televisão isso não é permitido (Becker, 2006).

As falhas decorrentes de performance, qualidade de áudio e vídeo e na utilização de programas, levam o usuário a uma negação do serviço de TVDI, provocando descrédito em toda a infraestrutura montada (Tonieto, 2006). Neste contexto, o sucesso de serviços de t-learning depende primariamente da confiabilidade do AVA utilizado para interagir com o usuário.

\section{e) Usabilidade}

A usabilidade pode ser definida como "até que ponto um produto pode ser usado por determinados usuários para atingir metas específicas com eficácia, eficiência e satisfação em um contexto de uso específico" (ISO 9241-11, 1998). No domínio da TVDI, a usabilidade se relaciona à facilidade de uso/interação com os aplicativos que estão sendo oferecidos.

De acordo com Aarreniemi-Jokipelto (2006), a usabilidade ruim pode afetar o aprendizado, de maneira que este, apesar de se estender ao longo de toda a vida, vincula diferentes necessidades com o passar do tempo. Os estudantes também podem ser portadores de necessidades especiais, e neste caso, requisitos de qualidade de som, textos e imagem podem variar conforme as necessidades do público-alvo.

\subsection{Requisitos pedagógicos}

Estes requisitos se referem às estratégias didáticas que o AVA deverá dar suporte. São elas: cessibilidade ao conteúdo, interação, avaliação, personalização da aprendizagem. 


\section{a) Acessibilidade ao conteúdo}

Um curso é formado por elementos como: objetivos do aprendizado, conteúdo pedagógico do curso, apresentação das informações, estudos de casos, ilustrações gráficas, vídeos, áudios, exercícios, entre outros. Porém, a qualidade do curso depende de como estes elementos serão dispostos, a sua acessibilidade e o cuidado com que eles serão estruturados (Moore; Kearsley, 2008).

Neste contexto, segundo Amaral (2004), o AVA deverá permitir que os programas educacionais para televisão possam ser estruturados de forma linear (a forma e a ordem do curso são determinadas pelo professor) e não linear (o estudante pode navegar pelo conteúdo da forma que melhor lhe convier), conforme ilustra a Figura 1.
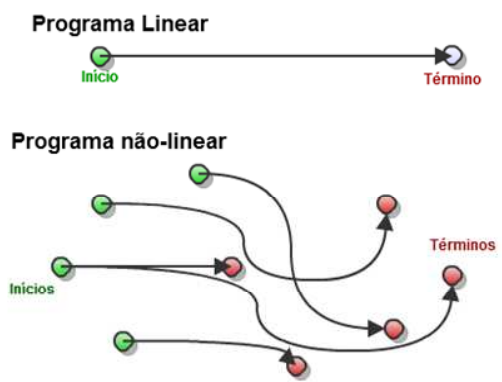

Figura 1 - Programação linear e não linear. Fonte: Amaral (2004).

\section{b) Interação}

A interação na TVDI pode ocorrer de forma síncrona (quando os conteúdos são exibidos ao usuário no mesmo momento da exibição do programa televisivo) ou assíncrona (quando os conteúdos podem ser consultados a qualquer momento) (Sancrini, 2008), conforme ilustrado na Figura 2.

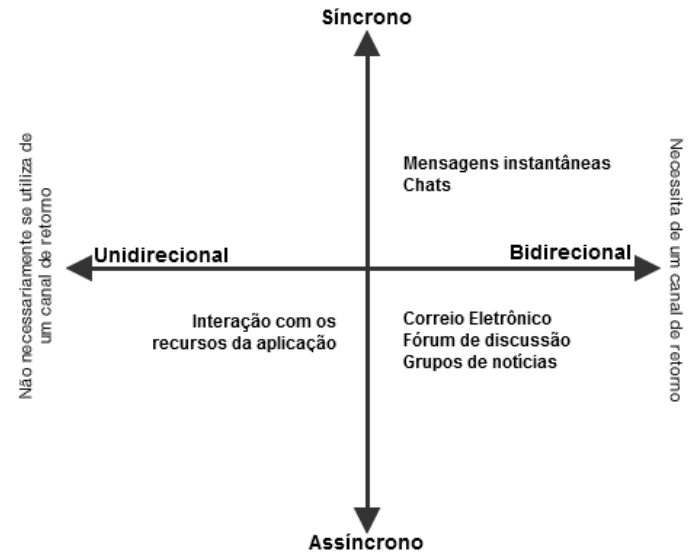

Figura 2 - Tipos de Interação e aplicativos na TVDI

Fonte: Zancanaro (2011).

A comunicação assíncrona na TVDI ocorre de forma unidirecional e bidirecional (Pataca et al, 2003). Nas aplicações unidirecionais, o estudante não troca informações com outros integrantes ou professor/tutor. Sua interação é com o sistema e localmente. Já, a forma bidirecional fornece suporte às aplicações assíncronas como correio eletrônico, fóruns de discussão e grupos de notícias. A comunicação síncrona, ou em tempo real, oferece suporte às aplicações do tipo chat ou mensagens instantâneas. 
c) Avaliação

Aarreniemi-Jokipelto (2006) propõe três tipos de avaliações no t-learning, conforme ilustradas na Figura 3.

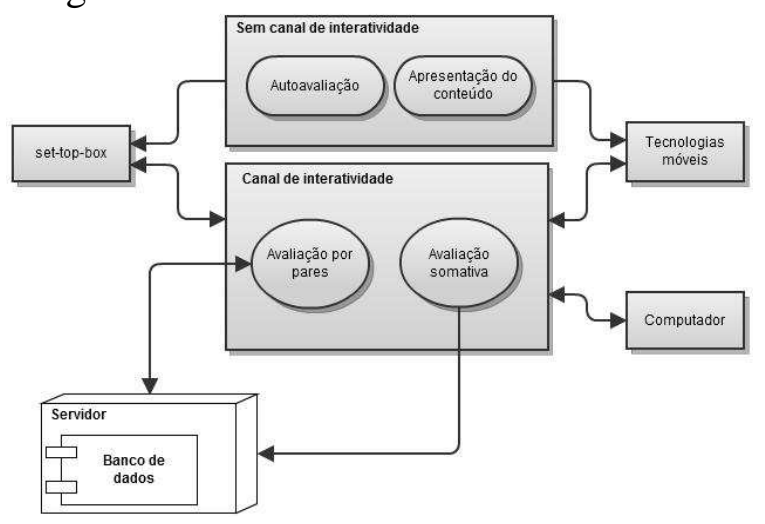

Figura 3 - Avaliações via TVDI e Internet Fonte: Zancanaro (2011).

$\mathrm{Na}$ autoavaliação (avaliação formativa) o próprio sistema oferece a correção imediatamente após a resposta do estudante. Neste caso, são interrupções na apresentação do conteúdo teórico, mediante questões propostas para o estudante, com o objetivo de reflexão sobre o assunto.

$\mathrm{Na}$ avaliação por pares (avaliação diagnóstico) ocorre a participação ativa no trabalho em grupo, além de estimular a discussão e o feedback. Pelo fato dos docentes não estarem o tempo todo presente, pode-se, de alguma forma, perder informações importantes a respeito do desempenho do estudante. Por isso, ouvir o ponto de vista dos colegas que têm outras experiências pode levar a mudanças positivas de comportamento.

Já avaliação somativa tem a função de avaliar a eficácia do curso e classificar o estudante atribuindo-lhe uma nota (Polak, 2009). Em cursos voltados para o t-learning, este tipo de avaliação requer um canal de retorno para que as notas sejam armazenadas em um banco de dados ou então, que a prova seja realizada presencialmente.

As questões usadas nas avaliações do t-learning podem ser no formato múltipla escolha, verdadeiro ou falso, associação, sequência (Olševičová, Rohrová e Mikulecká, 2007).

\section{d) Personalização da aprendizagem}

Diferentes formas de aprendizagem personalizada podem ser encontradas na literatura usando o t-learning. O modelo sugerido por Rey-López, Fernández-Vilas e Díaz-Redondo (2006) pode servir de exemplo. Nele, o objetivo é propor um sistema de tutoria inteligente que personaliza e apresenta o conteúdo baseado nas preferências do usuário. Outro exemplo é o descrito por Cmolik et al. (2007), no qual propuseram a personalização do conteúdo adicional, isto é, além daquele apresentado e controlado pela emissora. Neste caso, o conteúdo adicional é sincronizado ao fluxo de áudio e vídeo tendo como base o uso do padrão Scharable Content Objetc Reference Model (SCORM).

Em geral, o objetivo do ensino personalizado é fornecer um caminho de aprendizagem que é adaptado às necessidades e habilidades do estudante, resultando em maior eficiência no processo (Bellotti et al., 2008).

Para Aarreniemi-Jokipelto (2006), este método objetiva fornecer vários caminhos de aprendizagem para que estudantes, com diferentes objetivos e 
backgrounds, tenham condições de acompanhar os estudos individualmente.Erro! Fonte de referência não encontrada.

Para que isto seja possível, o início do curso é composto de questões que auxiliam na definição do caminho mais adequado a ser percorrido pelos estudantes. Esse caminho possui tarefas e objetivos diferentes.

O método se adapta a locais onde não existe um canal de interatividade instalado, não havendo a possibilidade do canal de transmissão enviar conteúdos específicos somente para um determinado receptor. Portanto, a solução de criar caminhos alternativos no conteúdo, parece ser uma solução viável.

A Figura 4 sintetiza os requisitos acima abordados.

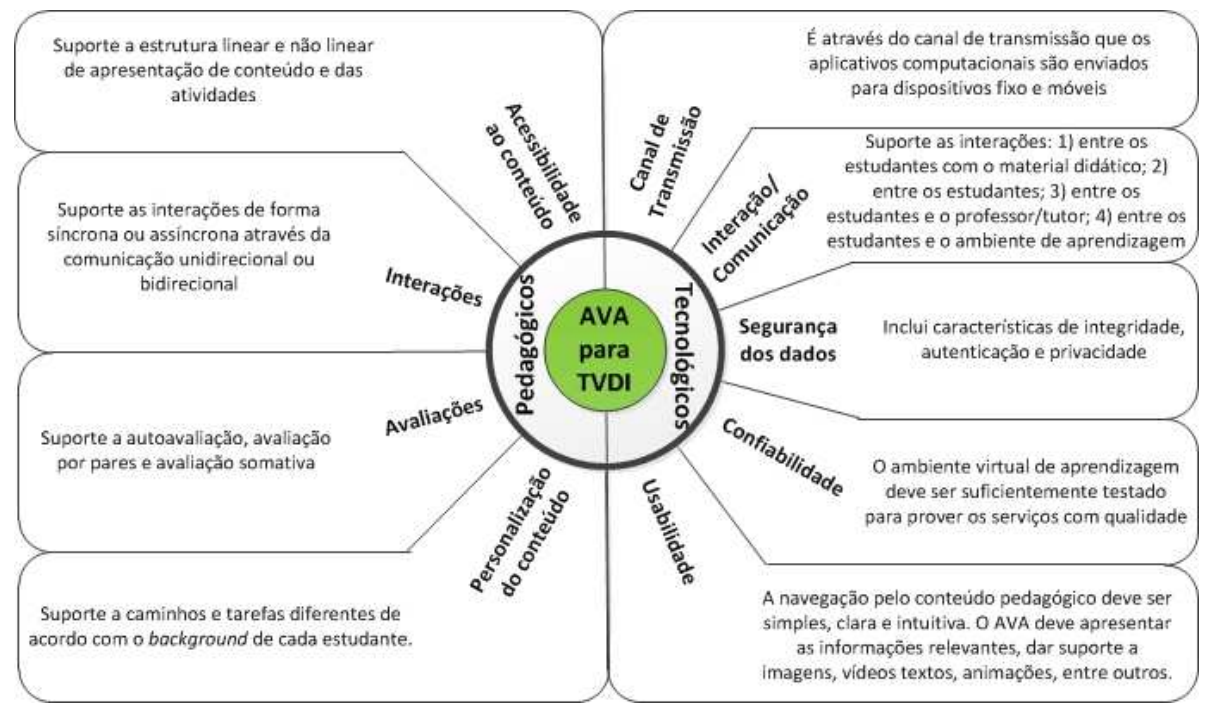

Figura 4 - Requisitos de um AVA para TVDI

\section{Conclusão e trabalhos futuros}

É certo que o desenvolvimento acelerado da tecnologia está produzindo uma mudança na forma de interagir e de se relacionar dos indivíduos. Esta mudança paradigmática já atinge também o processo de ensino/aprendizagem.

Tal influência está refletida principalmente na concepção dos novos AVAs que buscam, pouco a pouco, inserir o indivíduo num contexto de criação e compartilhamento de conhecimento, dando-lhe opções de participar ativamente da construção do saber.

Considerando a TV Digital como uma mídia bastante atrativa para suportar também a EaD, dada suas características e seu potencial interativo, o presente artigo buscou levantar os requisitos necessários para a disponibilização de um AVA na TVDI.

Considerando as particularidades dessa mídia, apresentamos como resultado os requisitos tecnológicos e pedagógicos, cuja explicitação visa auxiliar no desenvolvimento de ambientes propícios para o ensino/aprendizagem.

Como trabalhos futuros, sugere-se o desenvolvimento e a avaliação da consistência de um AVA voltado para a TVDI que leve em conta tais requisitos levantados.

\section{Referências bibliográficas}


AARRENIEMI-JOKIPELTO, P. T-learning Model for Learning via Digital TV. 16th EAEEIE Annual Conference on Innovation in Education for Electrical and Information Engineering (EIE). Lappeenranta, Finland: [s.n.]. 2005.

AARRENIEMI-JOKIPELTO, P. Modelling and content production of distance learning concept for interactive digital television. 2006. $204 \mathrm{f}$. Tese (Doutorado) Curso de Industrial Information Technology Laboratory, Department of Computer Science and Engineering, Helsinki University of Technology, Helsinki, 2006.

ALVES, J. R. M. A história da EAD no Brasil. In: LITTO, F. M.; FORMIGA, M. Educação a Distância: o estado da arte. São Paulo: Pearson Education, 2009. p. 9-13.

AMARAL, S. F. D. Serviço de apoio ao professor em sala de aula baseado na tv digital interativa. ABED, 2004.2 Disponível em: <http://www.abed.org.br/congresso2004/por/htm/003-TC-A1.htm>. Acesso em: 28 jul. 2010.

BATES, P. J. T-learning Study: A study into TV-based interactive learning to the home. Prepared by pjb Associates. This study has been conducted by pjb Associates, UK with funding from the European Community under the IST Programme (19982002). [S.1.]. 2003.

BECKER, V. Concepção e desenvolvimento de aplicações interativas para televisão digital. 2006. 100 f. Dissertação (Mestrado) - Curso de Engenharia e Gestão do Conhecimento, Engenharia do Conhecimento, Universidade Federal de Santa Catarina, Florianópolis, 2006.

BELDA, F. R. Um modelo estrutural de conteúdos educativos para televisão digital interativa. 2009. 292 f. Tese (Doutorado) - Curso de Escola de Engenharia de São Carlos, Engenharia de Produção, Universidade de São Paulo, São Carlos, 2009.

BELLONI, M. L. Educação a distância. Campinas: Editora Autores Associados, 1999.

BELlOTTI, F. et al. A T-learning Courses Development and Presentation Framework. IMCL International Conference on Mobile and Computer aided Learning 2008. Amman - Jordan: [s.n.]. 2008.

BRASIL. Decreto $N^{0} 5.622$ de 19 de dezembro de 2005 que regulamenta o art. 80 da Lei no 9.394, de 20 de dezembro de 1996, que estabelece as diretrizes e bases da educação nacional. Brasilia: DOU, 2005.

CMOLIK, L. et al. Personalized e-learning in interactive digital television environment. IADIS International Conference WWW/Internet 2007. Vila Real Portugal: [s.n.]. 2007. p. 35-39.

DAMÁSIO, M.; QUICO, C. T-Learning and Interactive Television Edutainment: the Portuguese Case Study. Proceedings of World Conference on Educational Multimedia, Hypermedia and Telecommunications 2004. Chesapeake, p. 4511-4518. 2004.

DILLENBOURG, Pierre. Virtual Learning Environment. EUN conference 2000: Learning in the new millennium: building new education strategies for schools. Workshop on virtual learning environments: University of Geneva, 2000.

FILATRO, A. Design Instrucional contextualizado: educação e tecnologia. São Paulo: Senac, 2004.

FILATRO, A. Design instrucional na prática. São Paulo: Pearson Education do Brasil, 2008. 
HOUAISS, A. Dicionário Houaiss da língua portuguesa. $1^{\mathrm{a}}$. ed. Rio de Janeiro: Objetiva, v. lix, 2009.

ISO 9241-11. Ergonomic requirements for office work with visual display terminals (VDTs) Par. ISO - International Standard. [S.1.]: [s.n.]. 1998.

JOCI. Convite à apresentação de propostas DG EAC/46/02 Acções preparatórias e inovadoras 2002/b. Jornal Oficial das Comunidades Europeias, p. 179/14 - 179/20, 27 jul. 2002.

MOORE, M.; KEARSLEY, G. Educação a Disitância: uma visão integrada. São Paulo: Cengage learning, 2008.

NORONHA, Adriana Backx; VIEIRA, Amanda Ribeiro. A utilização da plataforma WebCT para desenvolvimento e implementação de disciplinas utilizando a internet. In: BARBOSA, Rommel Melgaço (org). Ambientes virtuais de aprendizagem. Porto Alegre: Artmed, 2005.

NUNES, I. B. A história da EAD no Mundo. In: LITTO, F. M.; FORMIGA, M. Educação a Disitância: O estado da arte. São Paulo: Pearson Education do Brasil, 2009. p. 2-8.

OLŠEVIČOVÁ, K.; ROHROVÁ, H.; MIKULECKÁ, J. T-learning Approach: Enhancing Video with Active Elements. EC-TEL 2007 Posters, CEUR Workshop Proceedings, vol. 280. Crete, Greece : [s.n.]. 2007. p. 1-6.

PATACA, D. M. et al. Tecnologias de Serviços Educacionais em Plataforma de TV Digital. XXIII Congresso Brasileiro de Computação. Campinas. 2003. p. 401-409.

POLAK, Y. N. D. S. A avaliação do aprendiz em EaD. In: LITTO, F. M.; FORMIGA, M. Educação a Distância: o estado da arte. São Paulo: Pearson Education do Brasil, 2009. p. 153-160.

REY-LÓPEZ, M.; FERNÁNDEZ-VILA, A.; DÍAZ-REDONDO, R. P. A Model for Personalized Learning Through IDTV. A Model for Personalized Learning Through IDTV, in Adaptive Hypermedia, Adaptive Web-Based Systems 2006 (AH2006), Springer-Verlag, Editor. Dublin, Ireland: [s.n.]. 2006. p. 457-461.

ROCHA, A. R. C. D.; MALDONADO, J. C.; WEBER, K. C. Qualidade de software: Teoria e prática. São Paulo: Prentice Hall, 2001.

ROSENBERG, M. J. E-learning. São Paulo: Pearson Education, 2002.

SANCRINI, M. Televisão Digital: atributos tecnológicos e princípios pedagógicos para implementação no contexto escolar. 2008. 318 f. Dissetação (Mestrado) - Curso de Faculdade de Educação, Educação, Universidade de São Paulo, São Paulo, 2008.

SCHLEMMER, Eliane. Metodologias para educação a distância no context da formação de comunidades virtuais de aprendizagem. In: BARBOSA, Rommel Melgaço (org). Ambientes virtuais de aprendizagem. Porto Alegre: Artmed, 2005.

TANNOUS, Katia; ROPOLI, Edilene Aparecida. Trabalho com projetos como proposta pedagógica em cursos de engenharia química. In: BARBOSA, Rommel Melgaço (org). Ambientes virtuais de aprendizagem. Porto Alegre: Artmed, 2005.

TONIETO, M. T. Sistema brasileiro de TV Digital - SBTVD: uma análise política e tecnológica na inclusão social. 2006. 296 f. Dissertação (Mestrado) - Curso de Mestrado Profissionalizante em computação aplicada, Centro, Centro Federal de Educação Tecnológica do Ceará (CEFET-CE), Fortaleza, 2006. 
TORRES, Carlos Alberto. A Universidade Aberta de Brasília. In: Educação à Distância, v. 3, n. 4 e 5, p. 33-34, dez/93-abr/94, Brasília, INED.

ZANCANARO, Airton. Conhecimento envolvido na construção de conteúdo para TV Digital Interativa na EaD. 2011. 196 f. Dissertação (Mestrado) - Departamento de Engenharia do Conhecimento, Universidade Federal de Santa Catarina, Florianópolis, 2011. 